\title{
Letter
}

\section{Efficient and Stable Solution-Processed Organic Light Emitting Transistors using a High-k Dielectric}

Sungho Nam, Mujeeb Ullah Chaudhry, Kornelius Tetzner, Christopher Pearson, Chris Groves, Michael C. Petty, Thomas D. Anthopoulos, and Donal D.C. Bradley

ACS Photonics, Just Accepted Manuscript • DOI: 10.1021/acsphotonics.9b01265 • Publication Date (Web): 12 Nov 2019

Downloaded from pubs.acs.org on November 12, 2019

\section{Just Accepted}

"Just Accepted" manuscripts have been peer-reviewed and accepted for publication. They are posted online prior to technical editing, formatting for publication and author proofing. The American Chemical Society provides "Just Accepted" as a service to the research community to expedite the dissemination of scientific material as soon as possible after acceptance. "Just Accepted" manuscripts appear in full in PDF format accompanied by an HTML abstract. "Just Accepted" manuscripts have been fully peer reviewed, but should not be considered the official version of record. They are citable by the Digital Object Identifier (DOI®). "Just Accepted" is an optional service offered to authors. Therefore, the "Just Accepted" Web site may not include all articles that will be published in the journal. After a manuscript is technically edited and formatted, it will be removed from the "Just Accepted" Web site and published as an ASAP article. Note that technical editing may introduce minor changes to the manuscript text and/or graphics which could affect content, and all legal disclaimers and ethical guidelines that apply to the journal pertain. ACS cannot be held responsible for errors or consequences arising from the use of information contained in these "Just Accepted" manuscripts. 


\title{
Efficient and Stable Solution-Processed Organic Light
}

\section{Emitting Transistors using a High-k Dielectric}

\author{
Sungho Nam ${ }^{\dagger}$ Mujeeb Ullah Chaudhry ${ }^{*}$, Kornelius Tetzner $\$$, Christopher Pearson $\$$, Chris \\ Groves ${ }^{\ddagger}$, Michael C. Petty ${ }^{\ddagger}$,Thomas D. Anthopoulos ${ }^{*}, \|$ and Donal D. C. Bradley ${ }^{* \dagger, \perp, \|}$
}

†Department of Physics, University of Oxford, Oxford OX1 3PD, United Kingdom

Department of Engineering, Durham University, Durham, DH1 3LE, United Kingdom

$\S$ Blackett Laboratory, Department of Physics and Centre for Plastic Electronics, Imperial College London, London SW7 2BW, United Kingdom

"Physical Science and Engineering Division, King Abdullah University of Science and Technology (KAUST), KAUST Solar Centre, Thuwal 23955-6900, Saudi Arabia

${ }^{\perp}$ Department of Engineering Science, University of Oxford, Oxford OX1 3PJ, United Kingdom

\footnotetext{
*Corresponding Authors: mujeeb.u.chaudhry@durham.ac.uk, thomas.anthopoulos@kaust.edu.sa, donal.bradley@kaust.edu.sa
} 


\begin{abstract}
:
We report the development of highly efficient and stable solution-processed organic light emitting transistors (OLETs) that combine a polymer heterostructure with the transparent high- $k$ dielectric poly(vinylidenefluoride ${ }_{0.62}$-trifluoroethylene ${ }_{0.31}$-chlorotrifluoroethylene ${ }_{0.7}$ ) (P(VDF-TrFE-CTFE)). The polymer heterostructure comprises of the poly[4-(4,4dihexadecyl-4H-cyclopenta[1,2-b:5,4-b']dithiophen-2-yl)-alt-[1,2,5]thiadiazolo[3,4c]pyridine] (PCDTPT) and Super Yellow as charge transporting and light emitting layers, respectively. Device characterization shows that the use of P(VDF-TrFE-CTFE) leads to larger channel currents $(\approx 2 \mathrm{~mA})$ and lower operating voltages $(-35 \mathrm{~V})$ than for previously reported polymer based OLETs. Furthermore, the combined transparency of the dielectric and gate electrode, results in efficient bottom emission with external quantum efficiency of $\approx 0.88 \%$ at a luminance $\mathrm{L} \geq 2000 \mathrm{~cd} \mathrm{~m}^{-2}$. Importantly, the resulting OLETs exhibit excellent shelf life and operational stability. The present work represents a significant step forward in the pursuit of all-solution-processed OLET technology for lighting and display applications.
\end{abstract}

KEYWORDS: organic light-emitting transistors, high-k dielectric, polyvinylidene

fluoride copolymer 


\section{INTRODUCTION}

Organic light-emitting diodes (OLEDs) are now recognized as an important technology for application in ultrathin flexible displays on plastic or metal foil-base substrates. OLED based smart phones and large-size TVs have already entered the market, with the majority of these products utilizing rigid glass substrates. Despite the tremendous progress however, improvements in power efficiency, lifetime and cost are still needed in order to realize the full potential of the technology. ${ }^{1-3}$ Such requirements are even more pertinent for lighting and have driven development of solution-based fabrication processes that will also impact on the display sector. ${ }^{4-5}$ Additionally, the control circuitry that drives the OLED pixels needs to transition from the rigid and brittle inorganic semiconductor technologies to soluble semiconductors deposited at low temperature which will enable integration with flexible plastic substrates. However, the low carrier mobility of organic semiconductors is not yet sufficient for such current-driven display backplanes ${ }^{6-8}$ and oxide semiconductors look more 
promising in the first instance, albeit with the added challenge to deposit these materials at appropriate temperatures. ${ }^{9}$

An alternative to an OLED with associated drive circuitry is to combine the functionality of switching and light-emission in a single device, an organic light-emitting transistor (OLET). ${ }^{10-12}$ The latter combines both light-emitting and switching functions in a single device. Because of this multi-functionality, OLETs provide great promise for simple processing of advanced pixel architectures. ${ }^{13-16}$

Despite the significant progress that has already been made in the performance of OLETs, there are still numerous technical obstacles that need to be overcome, including the simultaneous achievement of high luminance, high external quantum efficiency (EQE) and low voltage operation. ${ }^{17-21}$ A key strategy to increase the driving current capabilities while reducing the operating voltage is to introduce high- $k$ gate dielectrics. Previously, OLETs with low operation voltages $(\sim 10 \mathrm{~V})$ have been reported employing $\mathrm{Al}_{2} \mathrm{O}_{3} / \mathrm{PMMA}$ and $\mathrm{Al}_{2} \mathrm{O}_{3} / \mathrm{ZrOx}$ bilayer gate dielectrics, however, the $\mathrm{Al}_{2} \mathrm{O}_{3}$ thin films were deposited by atomic layer deposition (ALD), which has a slow deposition rate and the $\mathrm{Al}_{2} \mathrm{O}_{3} / \mathrm{ZrO}_{\mathrm{x}}$ bilayer required ozone exposure and a photochemical curing step. ${ }^{22-23}$ In addition, OLETs with a thermally deposited trilayer organic stack and a poly(vinylidenefluoride-trifluoroethylenechlorotrifluoroethylene) $\mathrm{P}(\mathrm{VDF}-\mathrm{TrFE}-\mathrm{CFE})$ dielectric have been reported to exhibit higher EQE with reduced operating voltage, when compared to those with a low- $k$ poly(methyl methacrylate) (PMMA) dielectric layer. ${ }^{24-26}$ However, the P(VDF-TrFE-CTFE) polymer has not been used in OLETs before despite its intriguing properties, including high- $k$, outstanding electromechanical response, and low dielectric leakage. ${ }^{27-31}$

Here, we demonstrate efficient and stable, multi-layer solution-processed OLETs in a noncoplanar electrode structure comprising the high- $k$ dielectric P(VDF-TrFE-CTFE), a chargetransporting layer of poly[4-(4,4-dihexadecyl-4H-cyclopenta[1,2-b:5,4-b']dithiophen-2-yl)- 
alt-[1,2,5]thiadiazolo[3,4-c]pyridine] (PCDTPT), and a light-emissive layer of the Super Yellow polymer. The P(VDF-TrFE-CTFE) dielectric exhibited excellent endurance and the devices consequently showed high operational stability and device lifetime. Carefully engineered bottom emission OLETs exhibited Luminance of $>2000 \mathrm{~cd} / \mathrm{m}^{2}$ and an EQE value of $\sim 0.88 \%$.

\section{EXPERIMENTAL SECTION}

\subsection{Transistor Fabrication and Characterization.}

Super Yellow (PDY-132), poly[4-(4,4-dihexadecyl-4H-cyclopenta[1,2-b:5,4b']dithiophen-2-yl)-alt-[1,2,5] thiadiazolo[3,4-c]pyridine $] \quad$ (PCDTPT), and poly(vinylidenefluoride ${ }_{0.62}$-trifluoroethylene ${ }_{0.31}$-chlorotrifluoroethylene $\left.{ }_{0.7}\right) \quad(\mathrm{P}(\mathrm{VDF}-\mathrm{TrFE}-$ CTFE)) polymers (see Figure 1 (a) for chemical structures) were purchased from Merck, 1Material and Piezotech Arkema. Super Yellow and PCDTPT were dissolved in toluene and chlorobenzene at $7 \mathrm{mg} / \mathrm{mL}$ and $5 \mathrm{mg} / \mathrm{mL}$ concentration, respectively. A 2-butanone solution of $\mathrm{P}(\mathrm{VDF}-\mathrm{TrFE}-\mathrm{CTFE})$ was prepared at a concentration of $30 \mathrm{mg} / \mathrm{mL}$ and vigorously stirred overnight. The P(VDF-TrFE-CTFE) solution was spin-coated (1500 rpm, $60 \mathrm{~s}, 300 \mathrm{~nm}-$ thickness layer) on ITO-glass substrates pre-patterned to form the gate electrode and annealed at $100{ }^{\circ} \mathrm{C}$ for $20 \mathrm{~min}$. PCDTPT was spin-coated (2000 rpm, $40 \mathrm{~s}, 50-\mathrm{nm}$ thickness layer) on top of the $\mathrm{P}(\mathrm{VDF}-\mathrm{TrFE}-\mathrm{CTFE})$ layer, followed by annealing at $150{ }^{\circ} \mathrm{C}$ for $30 \mathrm{~min} . \mathrm{MoO}_{3}(\sim 5$ $\mathrm{nm})$ and $\mathrm{Au}(\sim 20 \mathrm{~nm})$ were then thermally deposited on top of the PCDTPT layer using a shadow mask to define the source electrode. Super Yellow was next spin-coated (2500 rpm, $30 \mathrm{~s}$ followed by $3000 \mathrm{rpm}, 10 \mathrm{~s}, 100-\mathrm{nm}$ thickness layer) and again annealed at $150{ }^{\circ} \mathrm{C}$ for 30 min. The device structure was completed by shadow-masked vacuum deposition of the drain 
electrode, comprising $\mathrm{Cs}_{2} \mathrm{CO}_{3}(\sim 5 \mathrm{~nm})$ capped with $\mathrm{Al}(\sim 20 \mathrm{~nm})$. The transistor channel length and width were $75 \mu \mathrm{m}$ and $14 \mathrm{~mm}$, respectively.

\subsection{Measurements.}

The electrical characterisation of the devices was performed within a nitrogen-filled glove box using an Agilent B2902A semiconductor parameter analyser. The capacitance-frequency (C-f) response of the P(VDF-TrFE-CTFE) layer was measured using a Fluxim Paios measurement system. Electroluminescence (EL) and photoluminescence (PL) spectra were measured using a UV-vis spectrometer (Ocean-Optics USB4000-XR). Charge carrier mobility was calculated from the transistors' transfer characteristics in the saturation regime. The luminance of the devices was determined from the photocurrent generated by a calibrated photodiode, referenced to a standard luminance meter (Minolta LS-100), taking into account the relative emission area. EQE was obtained from the luminance, source-drain current $\left(\mathrm{I}_{\mathrm{D}}\right)$, and emission spectra of the devices, assuming Lambertian emission. Tapping mode atomic force microscope (AFM) images were recorded using a Digital Instruments Dimension 3100 scanning probe microscope (SPM) with NanoScope IVa SPM control station. Optical transmission spectra, over the wavelength range $400-850 \mathrm{~nm}$, were measured using a Shimadzu UV-1800 spectrophotometer.

\section{RESULTS AND DISCUSSION}

Figure 1 shows a schematic of the device structure, the energy level alignments and a simplified operation model. Super Yellow was chosen as the emissive layer with PCDTPT as hole-transporting layer and $\mathrm{P}(\mathrm{VDF}-\mathrm{TrFE}-\mathrm{CTFE})$ as the high- $k$ gate dielectric. Improved charge injection into the organic layers was facilitated by the non-coplanar device structure 
with asymmetric source and drain (S-D) contacts (Figure 1 (b)). The device operation can be considered in terms of a combination OLED-transistor structure (Figure 1(c)). The highest occupied (HOMO) and lowest unoccupied (LUMO) molecular orbital levels of each material (Figure $1(b)$ ) are taken from the literature. ${ }^{32-34}$ As described in Figure 1(c), holes are injected from the $\mathrm{MoO}_{3} / \mathrm{Au}$ source contact into the HOMO energy level of the PCDTPT layer and subsequently transported across the channel by the PCDTPT layer. Electrons on the other hand are injected from the $\mathrm{Cs}_{2} \mathrm{CO}_{3} / \mathrm{Al}$ drain contact into the LUMO of the Super Yellow layer where they combine with holes to form excitons that decay radiatively generating optical photons. Here we note that the presence of $\mathrm{MoO}_{3}$ layer at the interface between $\mathrm{Au}$ and PCDTPT promotes contact doping that increases the electrical conductivity of the bulk film near the contact, thereby reducing contact resistance. ${ }^{35-36} \mathrm{In}$ addition, the $\mathrm{Cs}_{2} \mathrm{CO}_{3}$ electron injection interlayer can play an important role in lowering the work function of $\mathrm{Al}$ (ca. $-2.1 \mathrm{eV}$ for $\mathrm{Cs}_{2} \mathrm{CO}_{3} / \mathrm{Al} v s-4.2 \mathrm{eV}$ for $\mathrm{Al}$ ) by forming an Al-O-Cs complex. ${ }^{37}$

\section{Figure 1}

We first investigated the gate dielectric using a metal (ITO) - insulator (P(VDF-TrFECTFE)) - metal (Al) (MIM) structure, whose capacitance $v s$ frequency (C-f) response over the range 10 to $10 \mathrm{MHz}$ is shown in Figure 2(a). The capacitance decreased with increasing frequency as the polarization response time is limited by dipole alignment in the high- $k$ dielectric. ${ }^{38}$ The $\mathrm{P}(\mathrm{VDF}-\mathrm{TrFE}-\mathrm{CTFE})$ film capacitance (C) measured at $10 \mathrm{kHz}$ is 86.3 $\mathrm{nF} / \mathrm{cm}^{2}$, from which a $k$ value of 29.3 was calculated using the parallel plate capacitor equation $\left[\mathrm{C}=\left(\mathrm{k} \varepsilon_{0} \mathrm{~A}\right) / \mathrm{d}\right]$, with $\varepsilon_{0}, \mathrm{~A}$, and $\mathrm{d}$, being the vacuum permittivity, area of overlap of the electrodes, and film thickness, respectively. These $\mathrm{C}$ and $k$ values are comparable to those obtained from a $\mathrm{Si} / \mathrm{SiO}_{2} / \mathrm{P}(\mathrm{VDF}-\mathrm{TrFE}-\mathrm{CTFE}) / \mathrm{Al}$ capacitor (Figure $\left.\mathrm{S} 1\right)$. The relatively high 
breakdown voltage, demonstrating dielectric endurance up to $2.5 \mathrm{MV} / \mathrm{cm}(\approx 75 \mathrm{~V})$, is shown in the current density-electric field (J-E) graph (Figure 2(b)) and a leakage current density of less than $10^{-5} \mathrm{~A} / \mathrm{cm}^{2}$ was observed. We note that the $\mathrm{P}(\mathrm{VDF}-\mathrm{TrFE}-\mathrm{CTFE})$ dielectric layer did not reach its breakdown voltage in the studied bias range.

For full transistor structures, as shown in Figure 2(c), typical output characteristics (drain voltage $v s$ drain current, $\mathrm{V}_{\mathrm{D}}-\mathrm{I}_{\mathrm{D}}$ ) with distinct linear and saturation regimes were observed. Large $I_{D}$ values $\left(>1 \mathrm{~mA}\right.$ ) were observed when $V_{G}$ was biased at above $-20 \mathrm{~V}$ (see Figure 2(d)). Based on height-mode AFM images of P(VDF-TrFE-CTFE) and PCDTPT layers on glass and ITO-glass substrates (see Figure S2) both polymers form smooth layers; a root mean square roughness $0.92 \mathrm{~nm}, 1.74 \mathrm{~nm} 1.24 \mathrm{~nm}$ and $1.24 \mathrm{~nm}$ was found for P(VDFTrFE-CTFE) on glass, PCDTPT on glass, PCDTPT on P(VDF-TrFE-CTFE) coated glass and PCDTPT on P(VDF-TrFE-CTFE) coated ITO-glass, respectively. The surface morphology is uniform, facilitating lateral charge transport in the channel region and reducing charge trapping at the surface of the P(VDF-TrFE-CTFE) and PCDTPT layers. In addition, as shown in Figure 2(d), we observe the expected hysteresis between the forward and reverse scan transfer curves, associated with ferroelectric polarization switching in the high- $k$ dielectric. The hole mobilities $\left(\mu_{\mathrm{h}}\right)$ extracted from the transfer curves were 0.55 and $0.39 \mathrm{~cm}^{2} \mathrm{~V}^{-1} \mathrm{~s}^{-1}$ and threshold voltages $\left(\mathrm{V}_{\mathrm{TH}}\right)$ were -0.83 and $4.36 \mathrm{~V}$ for the forward and reverse scans, respectively. Both $\mu_{\mathrm{h}}$ and $\mathrm{V}_{\mathrm{TH}}$ were calculated in the saturation region using the gradual channel approximation model. The high capacitance of the P(VDF-TrFE-CTFE) layer allows low voltage operation due to the significant accumulation of holes at the PCDTPT/P(VDFTrFE-CTFE) interface.

\section{Figure 2}


The variation in luminance and EQE at $\mathrm{V}_{\mathrm{D}}=-35 \mathrm{~V}$ measured from the bottom and top of the device (c.f. Figure S3) are shown as a function of $V_{G}$ in Figures 3(a) and (b), respectively. The bottom emission luminance $\left(\mathrm{L}=2368.9 \mathrm{~cd} \mathrm{~m}^{-2}\right)$ at $\mathrm{V}_{\mathrm{G}}=-35 \mathrm{~V}$ was $\sim 13.6$ times higher than the top emission $\left(\mathrm{L}=174.5 \mathrm{~cd} \mathrm{~m}^{-2}\right)$. The higher luminance for the bottom emission was observed across a wide range of $\mathrm{V}_{\mathrm{D}}$ and $\mathrm{V}_{\mathrm{G}}$ values (see optical output characteristics in Figure S4). In addition, the EQE value for the bottom emission $(0.88 \%)$ was approximately one order of magnitude higher than for the top emission $(0.066 \%)$. Both EQE values saturate for $\left|\mathrm{V}_{\mathrm{G}}\right| \geq 20 \mathrm{~V}$ (Figure 3(b)), consistent with balanced hole and electron injection and minimal exciton quenching at high electric fields. The EQE is presented as a function of luminance in Figure 3(c), with good bottom emission performance achieved all the way up to $2500 \mathrm{~cd} / \mathrm{m}^{2}$. Also shown as an inset to Figure 3(c) is an image of Super Yellow emission emanating from such a device biased at $\mathrm{V}_{\mathrm{D}}=\mathrm{V}_{\mathrm{G}}=-35 \mathrm{~V}$. The observed hysteresis in the luminance / $\mathrm{EQE}$ vs $\mathrm{V}_{\mathrm{G}}$ curves between forward and reverse scans can be attributed to the ferroelectric properties of the P(VDF-TrFE-CTFE) layer leading to differing amounts of charge recombination. The electroluminescence (EL) spectrum for such an OLET is shown in Figure 3(d), closely overlapping but narrowed relative to the corresponding PL spectrum (Figure S5). The EL peaks at $\lambda=550 \mathrm{~nm}$, with the PL extending further into the red. Figure 3(d) also shows transmission spectra measured through an ITO-glass substrate coated with $\mathrm{P}(\mathrm{VDF}-\mathrm{TrFE}-\mathrm{CTFE})$ and PCDTPT $\left(\mathrm{T}_{\text {Bottom }}\right)$ and through a spectrosil substrate coated with $\mathrm{Cs}_{2} \mathrm{CO}_{3}$ and $\mathrm{Al}\left(\mathrm{T}_{\mathrm{Top}}\right)$, with layer thicknesses as used in the device. These samples therefore represent the light path from the Super Yellow emission layer in both directions through a half-stack but without accounting for microcavity resonance effects in the full stack structure. We observe that $\mathrm{T}_{\text {Bottom }}(565 \mathrm{~nm}) \approx 91.03 \%$ is significantly higher than $\mathrm{T}_{\text {Top }}(565 \mathrm{~nm}) \approx 19.3$ \%. The even higher EQE ratio between bottom emission and top emission is a consequence of the latter effects. 


\section{Figure 3}

Device operational stability was monitored over a $250 \mathrm{~s}$ time window for ITO-glass/ $\mathrm{P}\left(\right.$ VDF-TrFE-CTFE)/PCDTPT/Super Yellow/Cs $\mathrm{CO}_{3} / \mathrm{Al}$ OLETs, with $\mathrm{I}_{\mathrm{D}}$ and bottom emission luminance values continuously recorded under constant bias $\left(\mathrm{V}_{\mathrm{D}}=\mathrm{V}_{\mathrm{G}}=-35 \mathrm{~V}\right)$ and in ambient conditions. As shown in Figure $4(a), I_{D}$ decreased by a relatively modest amount $(\sim 11 \%)$ over this period, indicating relatively good electrical stability for an un-encapsulated structure. More importantly, Figure 4(b) demonstrates that only a marginal reduction by $\sim 2.1$ $\%$ in the device luminance occurred over the same period. Typically, both extrinsic (e.g. oxygen, water, and temperature) and intrinsic (e.g. excited state and charge carrier interactions) factors are complicit in degradation, with reductions in charge carrier mobility and charge injection efficiency previously reported to result. ${ }^{39}$ Our devices showed more stable charge carrier mobility and charge injection, leading to only a marginal reduction in device luminance over the period observed. A further study will be needed to explore the longer-term device lifetime and associated degradation mechanisms.

\section{Figure 4}

\section{CONCLUSIONS}

In conclusion, we have demonstrated efficient and stable solution-processed bottomemitting organic light emitting transistors using a high- $k$ dielectric in combination with an asymmetric electrode device architecture. The P(VDF-TrFE-CTFE) dielectric layer was shown to play a critical role in reducing the operating voltage while the asymmetric electrode 
architecture improved the hole and electron injection into the light emissive Super Yellow layer, leading to efficient radiative recombination. Importantly, the OLETs showed high maximum channel currents $(\approx 2 \mathrm{~mA})$, with a hole mobility $\mu_{\mathrm{h}}$ value in the range $0.39-0.55$ $\mathrm{cm}^{2} \mathrm{~V}^{-1} \mathrm{~s}^{-1}$. The high $\mu_{\mathrm{h}}$ together with the obtained EQE of $\approx 0.88 \%$ allows the luminance for bottom emission devices to reach values in excess of $2000 \mathrm{~cd} / \mathrm{m}^{2}$. Noticeably, the OLETs exhibited promising operating stability with peak EQE and luminance measured at maximum $\mathrm{I}_{\mathrm{D}}$. It is evident that introduction of a high-k dielectric can positively influence both the operational stability and lifetime of the OLETs. Our results thus present a significant opportunity to advance OLET performance towards efficient, bright and stable operation in numerous applications, including solid-state lighting, optical communications, smart pixels and integrated optoelectronic systems.

\section{- ASSOCIATED CONTENT}

\section{Supporting Information}

This material is available free of charge via the Internet at http://pubs.acs.org.

\section{- AUTHOR INFORMATION}

\section{Corresponding Authors}

*E-mail: mujeeb.u.chaudhry@durham.ac.uk, thomas.anthopoulos@kaust.edu.sa, donal.bradley@,kaust.edu.sa

\section{Notes}

The authors declare no competing financial interest.

\section{- ACKNOWLEDGMENT}


SN and DDCB thank the University of Oxford for postdoctoral research fellowship funding together with laboratory infrastructure and other research support. MUC acknowledges provision of a starting grant from Durham University and travel and subsistence support from the University of Oxford. KT and TDA further thank the European Union Horizon 2020 People Programme (Marie Curie Actions grant Nº58563, “Flexible Complementary Hybrid Integrated Circuits", (FlexCHIC)), and the King Abdullah University of Science and Technology (KAUST) for financial support.

\section{- REFERENCES}

(1) Kim, K. H.; Kim, J. J., Origin and control of orientation of phosphorescent and tadf dyes for high-efficiency OLEDs. Adv. Mater. 2018, 30, e1705600.

(2) Liu, Y.; Li, C.; Ren, Z.; Yan, S.; Bryce, M. R., All-organic thermally activated delayed fluorescence materials for organic light-emitting diodes. Nat. Rev. Mater. 2018, 3, 18020.

(3) Tang, C. W.; VanSlyke, S. A., Organic electroluminescent diodes. Appl. Phys. Lett. 1987, 51, 913-915.

(4) Maasoumi, F.; Jansen-van Vuuren, R. D.; Shaw, P. E.; Puttock, E. V.; Nagiri, R. C. R.; McEwan, J. A.; Bown, M.; O’Connell, J. L.; Dunn, C. J.; Burn, P. L.; Namdas, E. B., An external quantum efficiency of $>20 \%$ from solution- 
processed poly(dendrimer) organic light-emitting diodes. npj Flexible Electron. 2018, 2, 27.

(5) Perumal, A.; Faber, H.; Yaacobi-Gross, N.; Pattanasattayavong, P.; Burgess, C.; Jha, S.; McLachlan, M. A.; Stavrinou, P. N.; Anthopoulos, T. D.; Bradley, D. D. C., High-efficiency, solution-processed, multilayer phosphorescent organic light-emitting diodes with a copper thiocyanate hole-injection/hole-transport layer. Adv. Mater. 2015, 27, 93-100.

(6) Cui, N.; Ren, H.; Tang, Q.; Zhao, X.; Tong, Y.; Hu, W.; Liu, Y., Fully transparent conformal organic thin-film transistor array and its application as led front driving. Nanoscale 2018, 10, 3613-3620.

(7) Liu, J.; Qin, Z.; Gao, H.; Dong, H.; Zhu, J.; Hu, W., Vertical organic field-effect transistors. Adv. Funct. Mater. 2019, 29, 1808453.

(8) Choi, M.; Park, Y. J.; Sharma, B. K.; Bae, S.-R.; Kim, S. Y.; Ahn, J.-H., Flexible active-matrix organic light-emitting diode display enabled by mos2 thin-film transistor. 2018, 4, eaas8721. 
(9) Adamopoulos, G.; Thomas, S.; Wobkenberg, P. H.; Bradley, D. D.; McLachlan, M. A.; Anthopoulos, T. D., High-mobility low-voltage $\mathrm{ZnO}$ and Li-doped zno transistors based on $\mathrm{ZrO}_{2}$ high-k dielectric grown by spray pyrolysis in ambient air. Adv. Mater. 2011, 23, 1894-1898.

(10) Zhang, C.; Chen, P.; Hu, W., Organic light-emitting transistors: Materials, device configurations, and operations. Small2016, 12, 1252-1294.

(11) Wakayama, Y.; Hayakawa, R.; Seo, H. S., Recent progress in photoactive organic field-effect transistors. Sci. Technol. Adv. Mater. 2014, 15, 024202.

(12) Liu, C. F.; Liu, X.; Lai, W. Y.; Huang, W., Organic light-emitting field-effect transistors: Device geometries and fabrication techniques. Adv. Mater. 2018, 30, e1802466.

(13) Bisri, S. Z.; Takenobu, T.; Sawabe, K.; Tsuda, S.; Yomogida, Y.; Yamao, T.; Hotta, S.; Adachi, C.; Iwasa, Y., p-i-n homojunction in organic light-emitting transistors. Adv. Mater. 2011, 23, 2753-2758.

(14) Capelli, R.; Dinelli, F.; Gazzano, M.; D'Alpaos, R.; Stefani, A.; Generali, G.; Riva, M.; Montecchi, M.; Giglia, A.; Pasquali, L., Interface functionalities in 
multilayer stack organic light emitting transistors (OLETs). Adv. Funct. Mater. 2014, 24, 5603-5613.

(15) Muccini, M., A bright future for organic field-effect transistors. Nat. Mater. 2006, $5,605-613$.

(16) McCarthy, M. A.; Liu, B.; Donoghue, E. P.; Kravchenko, I.; Kim, D. Y.; Rinzler, A. G., Low-voltage, low-power, organic light-emitting transistors for active matrix displays. Science 2011, 29, 570-573.

(17) Ullah, M.; Armin, A.; Tandy, K.; Yambem, S. D.; Burn, P. L.; Meredith, P.; Namdas, E. B., Defining the light emitting area for displays in the unipolar regime of highly efficient light emitting transistors. Sci. Rep. 2015, 5, 8818.

(18) Ullah, M.; Tandy, K.; Yambem, S. D.; Aljada, M.; Burn, P. L.; Meredith, P.; Namdas, E. B., Simultaneous enhancement of brightness, efficiency, and switching in rgb organic light emitting transistors. Adv. Mater. 2013, 25, 62136218. 
(19) Namdas, E. B.; Hsu, B. B. Y.; Liu, Z.; Lo, S. C.; Burn, P. L.; Samuel, I. D. W., Phosphorescent light-emitting transistors: Harvesting triplet excitons. Adv. Mater. 2009, 21, 4957-4961.

(20) Zaumseil, J.; Friend, R. H.; Sirringhaus, H., Spatial control of the recombination zone in an ambipolar light-emitting organic transistor. Nat. Mater. 2005, 5, 6974.

(21) Muhieddine, K.; Ullah, M.; Pal, B. N.; Burn, P.; Namdas, E. B., All solutionprocessed, hybrid light emitting field-effect transistors. Adv. Mater. 2014, 26, 6410-6415.

(22) Ullah, M.; Wawrzinek, R.; Maasoumi, F.; Lo, S.-C.; Namdas, E. B., Semitransparent and low-voltage operating organic light-emitting field-effect transistors processed at low temperatures. Adv. Opt. Mater. 2016, 4, 10221026.

(23) Chaudhry, M. U.; Tetzner, K.; Lin, Y. H.; Nam, S.; Pearson, C.; Groves, C.; Petty, M. C.; Anthopoulos, T. D.; Bradley, D. D. C., Low-voltage solution- 
processed hybrid light-emitting transistors. ACS Appl. Mater. Interfaces 2018, 10, 18445-18449.

(24) Soldano, C.; D’Alpaos, R.; Generali, G., Highly efficient red organic lightemitting transistors (OLETs) on high-k dielectric. ACS Photon. 2017, 4, 800805.

(25) Pattanasattayavong, P.; Yaacobi-Gross, N.; Zhao, K.; Ndjawa, G. O.; Li, J.; Yan, F.; O'Regan, B. C.; Amassian, A.; Anthopoulos, T. D., Hole-transporting transistors and circuits based on the transparent inorganic semiconductor copper(i) thiocyanate (CuSCN) processed from solution at room temperature. Adv. Mater. 2013, 25, 1504-1509.

(26) Li, J.; Sun, Z.; Yan, F., Solution processable low-voltage organic thin film transistors with high-k relaxor ferroelectric polymer as gate insulator. $A d v$. Mater. 2012, 24, 88-93.

(27) Cho, Y.; Ahn, D.; Park, J. B.; Pak, S.; Lee, S.; Jun, B. O.; Hong, J.; Lee, S. Y.; Jang, J. E.; Hong, J.; Morris, S. M.; Sohn, J. I.; Cha, S. N.; Kim, J. M., Enhanced ferroelectric property of P(VDF-TrFE-CTFE) film using room- 
temperature crystallization for high-performance ferroelectric device applications. Adv. Electron. Mater. 2016, 2, 1600225.

(28) Hwang, S. K.; Bae, I.; Cho, S. M.; Kim, R. H.; Jung, H. J.; Park, C., High performance multi-level non-volatile polymer memory with solution-blended ferroelectric polymer/high-k insulators for low voltage operation. Adv. Funct. Mater. 2013, 23, 5484-5493.

(29) Kim, J.; Lee, J. H.; Ryu, H.; Lee, J.-H.; Khan, U.; Kim, H.; Kwak, S. S.; Kim, S.W., High-performance piezoelectric, pyroelectric, and triboelectric nanogenerators based on $\mathrm{P}(\mathrm{VDF}-\mathrm{TrFE})$ with controlled crystallinity and dipole alignment. Adv. Funct. Mater. 2017, 27, 1700702.

(30) Knotts, G.; Bhaumik, A.; Ghosh, K.; Guha, S., Enhanced performance of ferroelectric-based all organic capacitors and transistors through choice of solvent. Appl. Phys. Lett. 2014, 104, 233301.

(31) Lee, J. H.; Jeong, B.; Cho, S. H.; Kim, E. H.; Park, C., Non-volatile polymer electroluminescence programmable with ferroelectric field-induced charge injection gate. Adv. Funct. Mater. 2016, 26, 5391-5399. 
(32) Tseng, H. R.; Ying, L.; Hsu, B. B.; Perez, L. A.; Takacs, C. J.; Bazan, G. C.; Heeger, A. J., High mobility field effect transistors based on macroscopically oriented regioregular copolymers. Nano Lett. 2012, 12, 6353-6357.

(33) Tseng, H. R.; Phan, H.; Luo, C.; Wang, M.; Perez, L. A.; Patel, S. N.; Ying, L.; Kramer, E. J.; Nguyen, T. Q.; Bazan, G. C.; Heeger, A. J., High-mobility fieldeffect transistors fabricated with macroscopic aligned semiconducting polymers. Adv. Mater. 2014, 26, 2993-2998.

(34) Ullah, M.; Tandy, K.; Yambem, S. D.; Muhieddine, K.; Ong, W. J.; Shi, Z.; Burn, P. L.; Meredith, P.; Li, J.; Namdas, E. B., Efficient and bright polymer light emitting field effect transistors. Org. Electron. 2015, 17, 371-376.

(35) Choi, S.; Fuentes-Hernandez, C.; Wang, C. Y.; Khan, T. M.; Larrain, F. A.; Zhang, Y.; Barlow, S.; Marder, S. R.; Kippelen, B., A study on reducing contact resistance in solution-processed organic field-effect transistors. ACS Appl. Mater. Interfaces 2016, 8, 24744-24752. 
(36) Ablat, A.; Kyndiah, A.; Houin, G.; Alic, T. Y.; Hirsch, L.; Abbas, M., Role of oxide/metal bilayer electrodes in solution processed organic field effect transistors. Sci. Rep. 2019, 9, 6685.

(37) Huang, J.; Xu, Z.; Yang, Y., Low-work-function surface formed by solutionprocessed and thermally deposited nanoscale layers of cesium carbonate. $A d v$. Funct. Mater. 2007, 17, 1966-1973.

(38) Baeg, K. J.; Khim, D.; Kim, J.; Han, H.; Jung, S. W.; Kim, T. W.; Kang, M.; Facchetti, A.; Hong, S. K.; Kim, D. Y.; Noh, Y. Y., Controlled charge transport by polymer blend dielectrics in top-gate organic field-effect transistors for lowvoltage-operating complementary circuits. ACS Appl. Mater. Interfaces 2012, 4, 6176-6184.

(39) Niu, Q.; Rohloff, R.; Wetzelaer, G. A. H.; Blom, P. W. M.; Craciun, N. I., Hole trap formation in polymer light-emitting diodes under current stress. Nat. Mater. $2018,17,557-562$. 
(a)

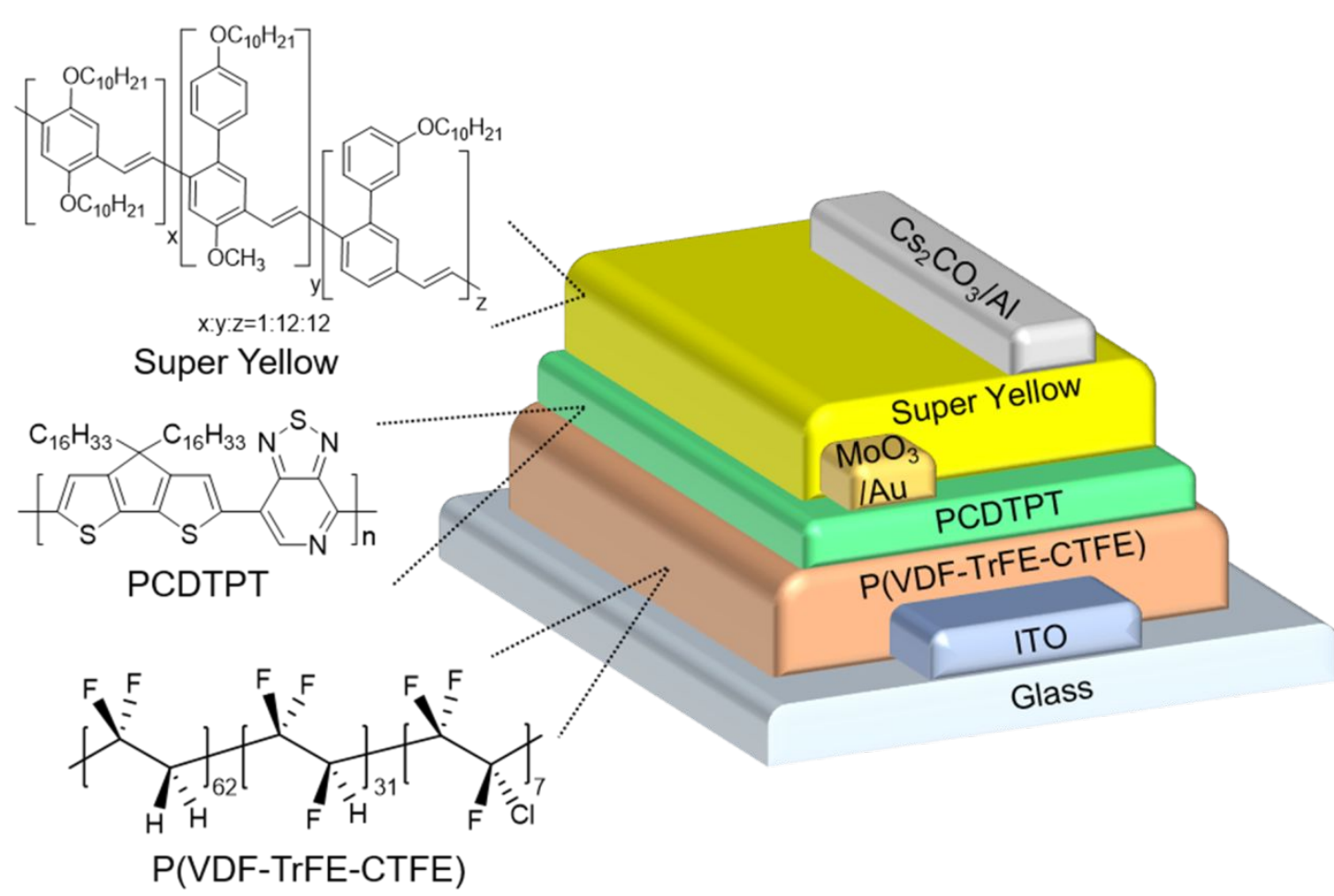

(b)

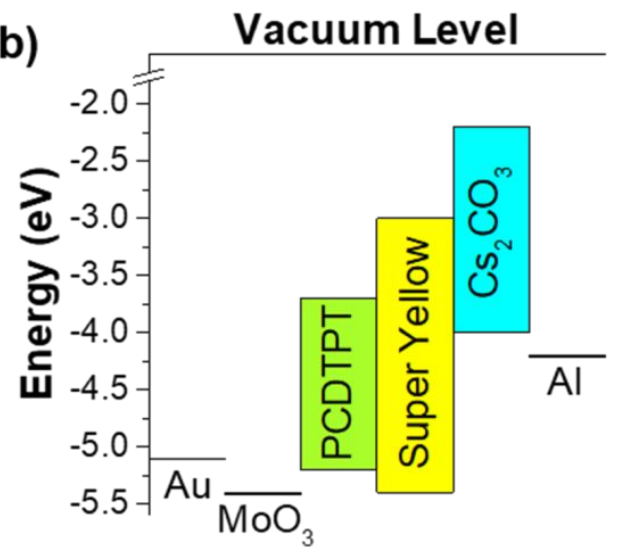

(c)

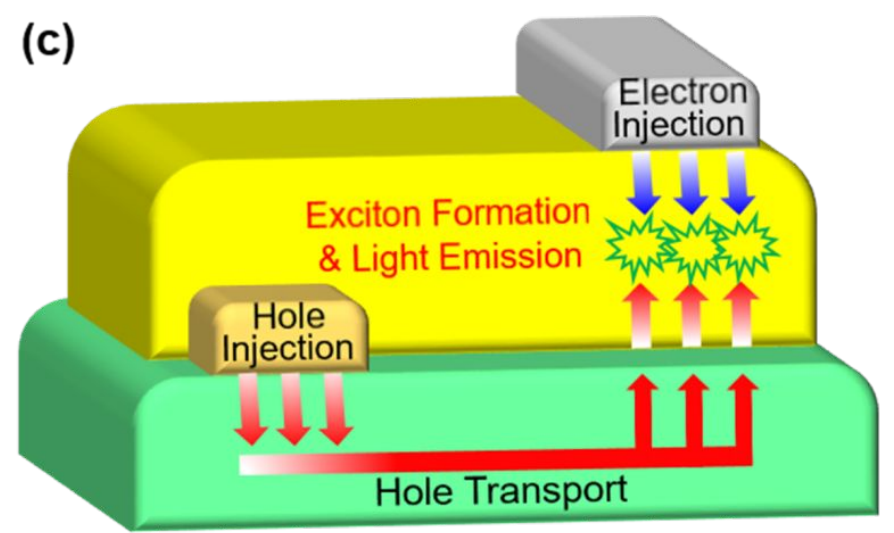

Figure 1. (a) Chemical structures of Super Yellow, PCDTPT, and $\mathrm{P}\left(\mathrm{VDF}_{0.62}-\mathrm{TrFE}_{0.31^{-}}\right.$ $\mathrm{CTFE}_{0.7}$ ) polymer light-emitting, hole-transporting, and gate dielectric layer materials, respectively; also shown is a schematic device structure. (b) Energy level diagram for the studied organic light-emitting transistor structures with asymmetric source-drain electrodes. (c) Schematic depiction of the operating mechanism of the OLETs, showing hole injection from the source electrode into PCDTPT, lateral hole transport, electron injection from the drain electrode into Super Yellow, exciton formation within that layer and light emission therefrom. 
(a)

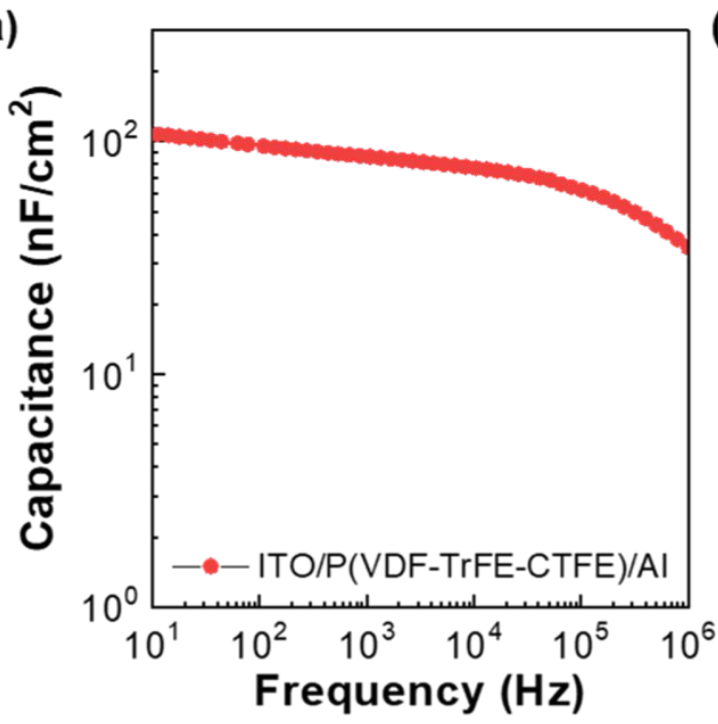

(c)

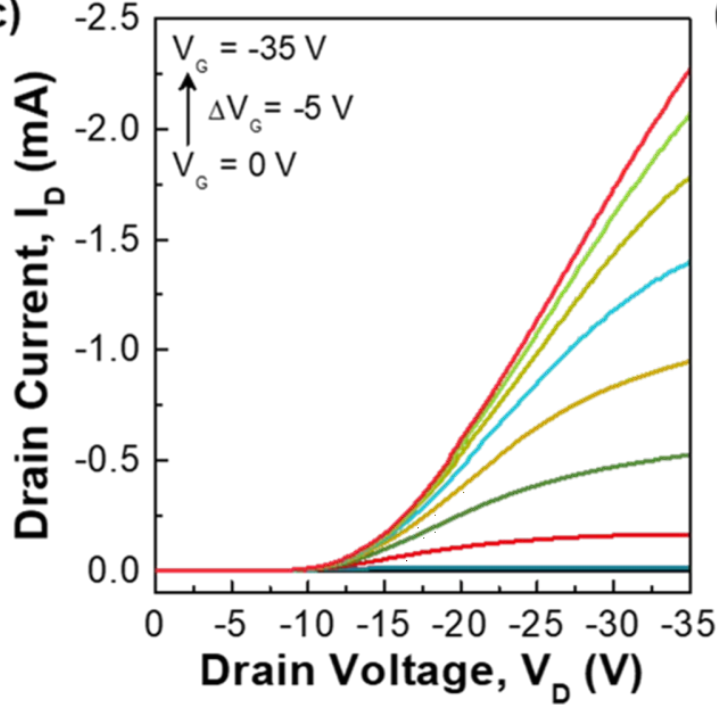

(b)

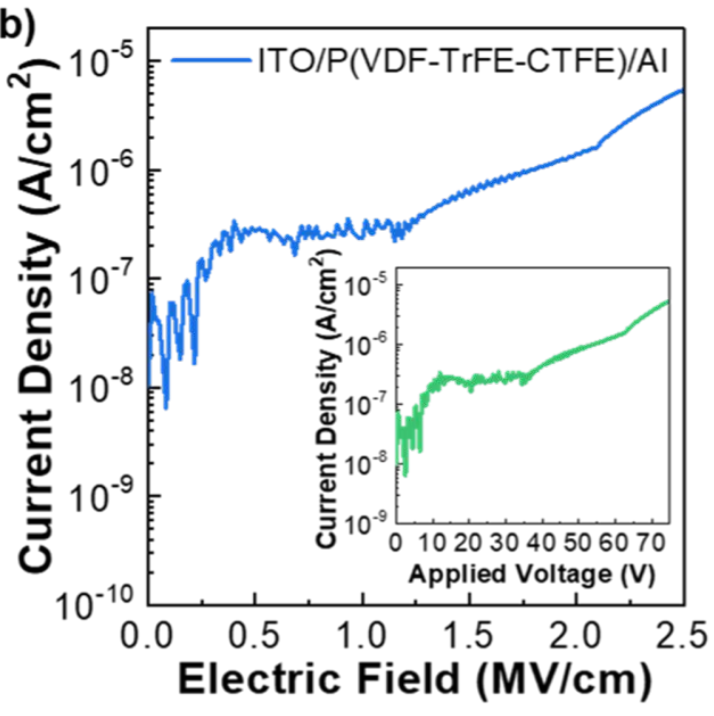

(d)

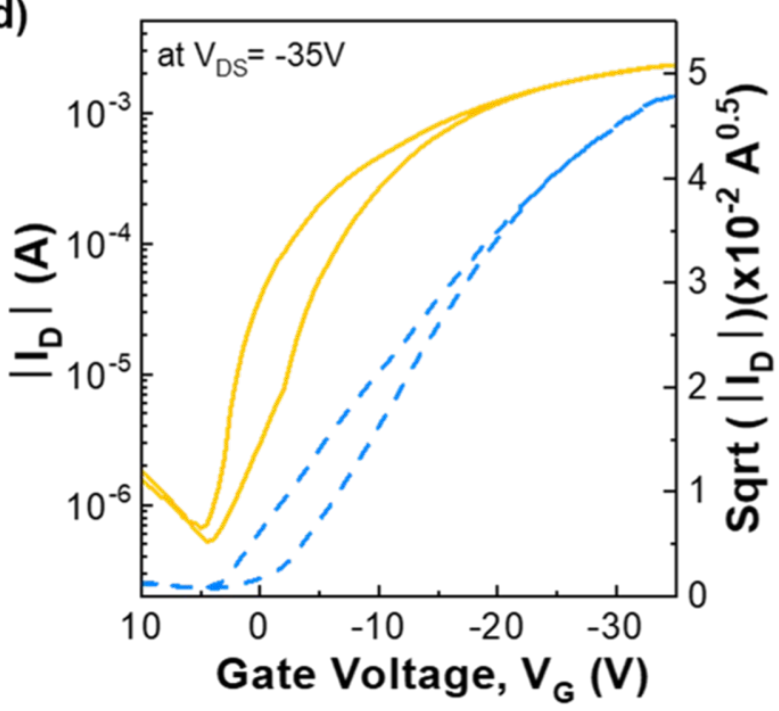

Figure 2. (a) Capacitance-frequency, and (b) current density-electric field characteristics for MIM capacitor structures comprising ITO/P(VDF-TrFE-CTFE)/Al. (c) Output and (d) transfer curves for the studied OLETs. 
(a)

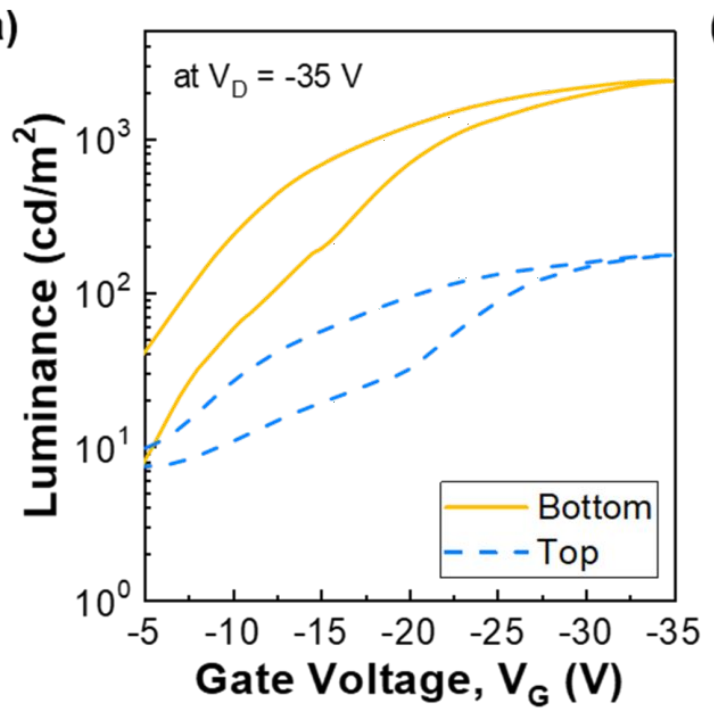

(c)

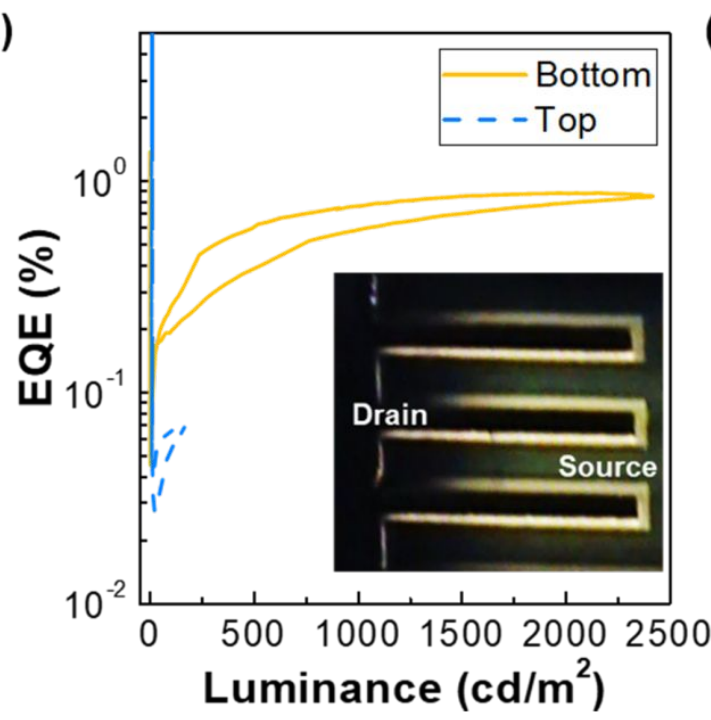

(b)

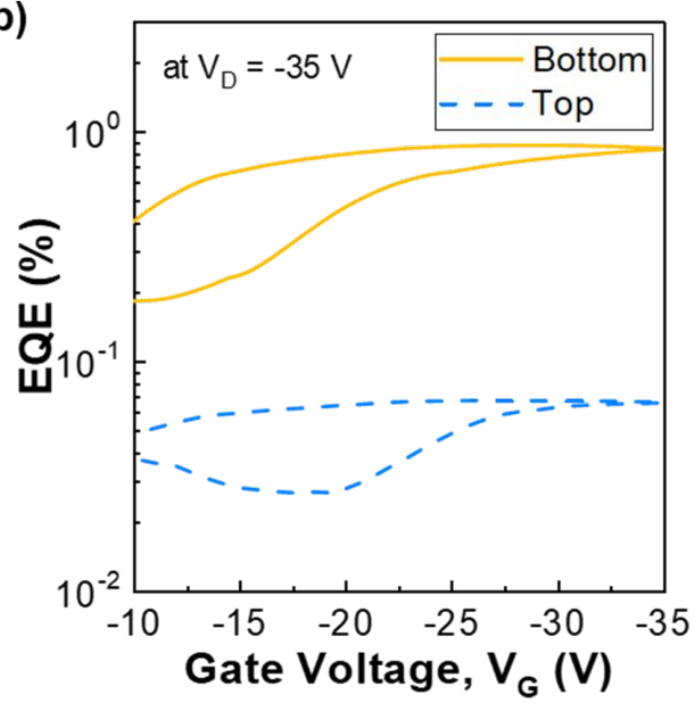

(d)

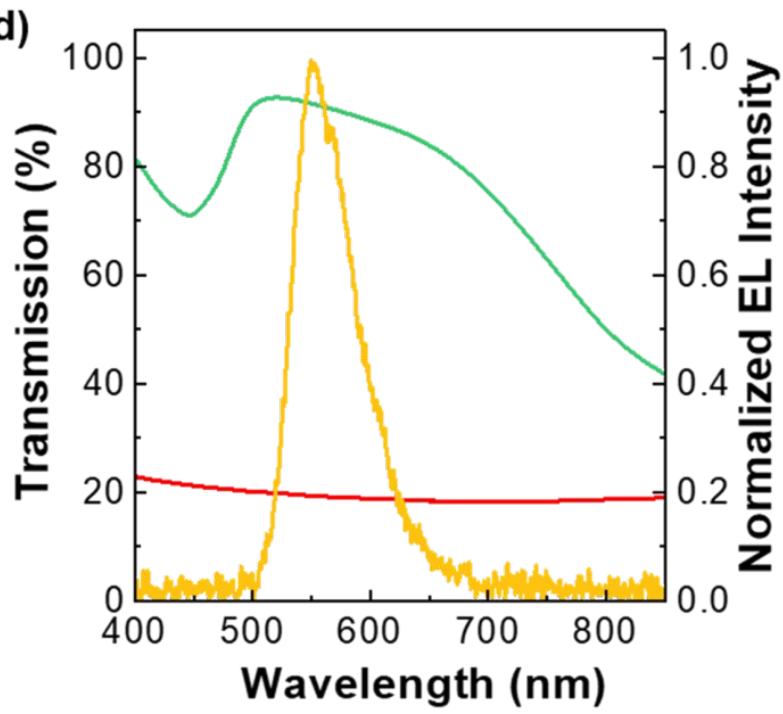

Figure 3. (a) Optical transfer characteristics, (b) external quantum efficiency (EQE), and (c) $\mathrm{EQE}$ as a function of device luminance for both top and bottom emission directions. Inset in (c) shows an OLET during operation. (d) Normalized electroluminescence (EL) spectrum and transmittance spectra for the top $\left(\mathrm{Cs}_{2} \mathrm{CO}_{3} / \mathrm{Al}\right.$; red line) and bottom (glass/ITO/P(VDF-TrFECTFE)/PCDTPT; green line) electrode stacks. 
(a)

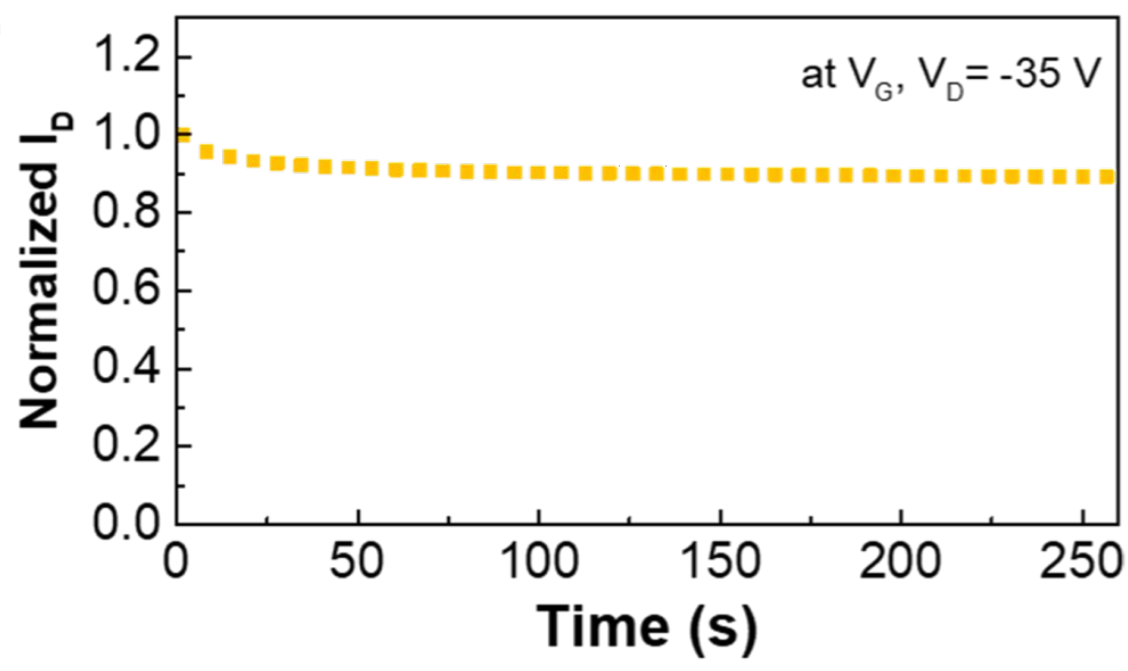

(b)

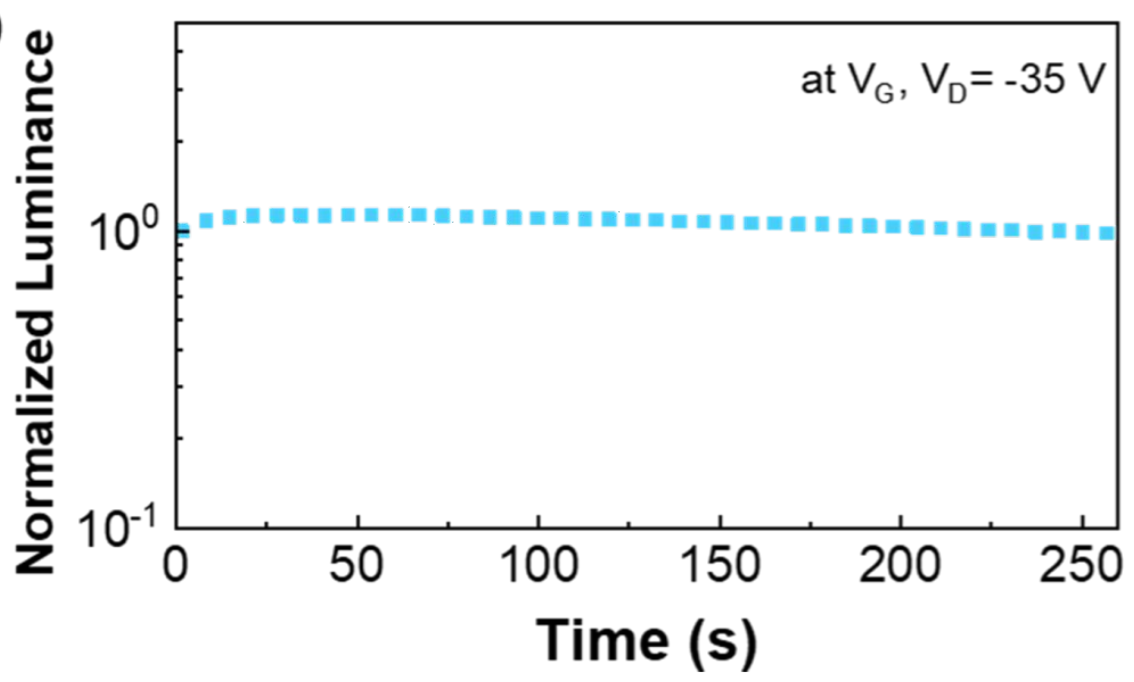

Figure 4. Operational stability for a PCDTPT/Super Yellow OLET. (a) Normalized $\mathrm{I}_{\mathrm{D}}$, and (b) normalized luminance under constant driving conditions of $\mathrm{V}_{\mathrm{G}}=\mathrm{V}_{\mathrm{D}}=-35 \mathrm{~V}$. 
Table 1. Performance parameters of high-k dielectric-based OLETs (Note that all transistor parameters were extracted from more than 5 devices and the averaged values are displayed).

\begin{tabular}{ccccc}
\hline $\begin{array}{c}\text { Mobility } \\
\left(\mathrm{cm}^{2} \mathrm{~V}^{-1} \mathrm{~s}^{-1}\right)\end{array}$ & On/off ratio & $\begin{array}{c}\text { Vth } \\
(\mathrm{V})\end{array}$ & $\begin{array}{c}\text { EQE } \\
(\%)\end{array}$ & $\begin{array}{c}\text { Luminance } \\
\left(\mathrm{cd} \mathrm{m}^{-2}\right)\end{array}$ \\
\hline $0.55 / 0.39$ & $4340 / 3460$ & $-0.83 / 4.36$ & $0.11 / 0.88$ & $180 / 2422$ \\
(Forward $/$ & (Forward $/$ & (Forward / & $\begin{array}{c}\text { (Top / Bottom } \\
\text { Emission) }\end{array}$ & $\begin{array}{c}\text { (Top / Bottom } \\
\text { Emission) }\end{array}$ \\
Backward) & Backward) & Backward) & .
\end{tabular}


$<$ TOC Graphic>
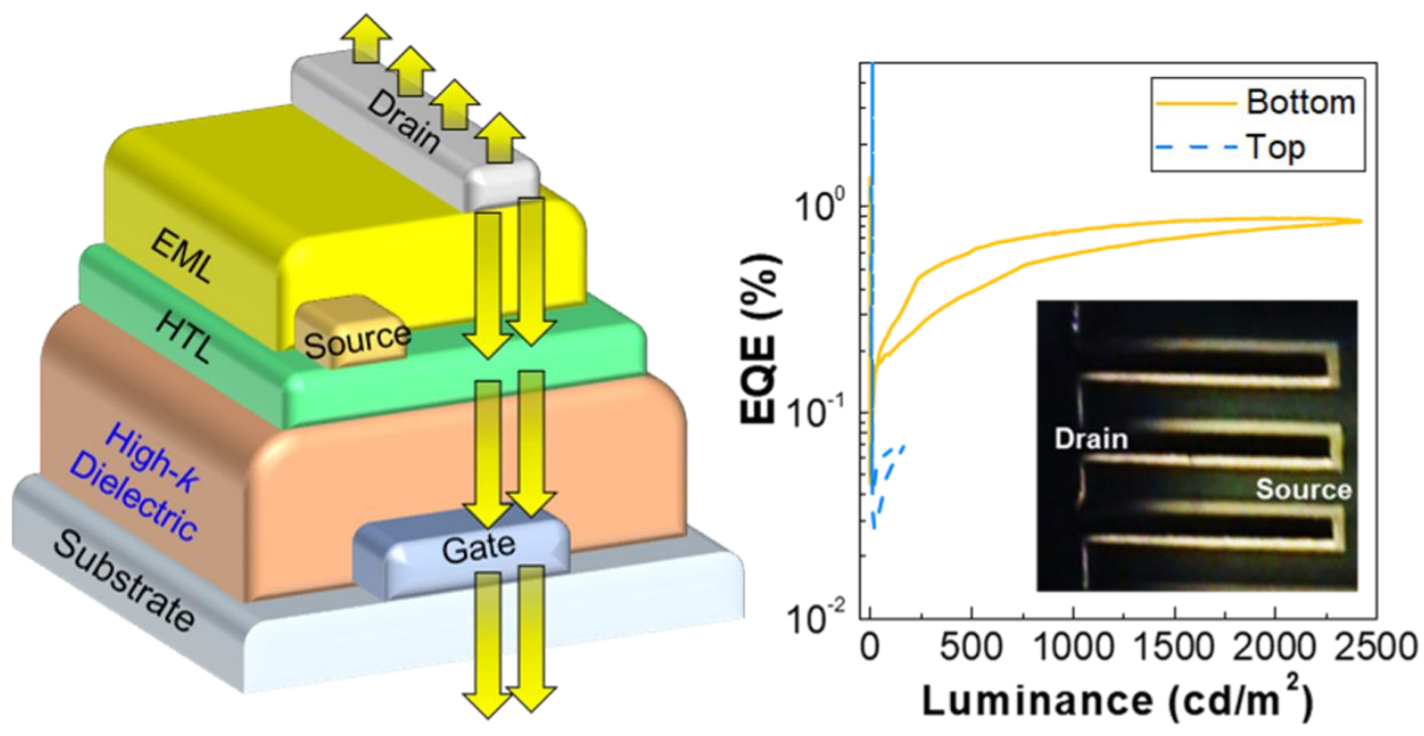